\title{
Correspondence: Guillain-Barré syndrome and hemorrhagic fever with renal syndrome
}

\author{
Linpei $\mathrm{Jia}^{1+}$, Rufu $\mathrm{Jia}^{2+}$ and Hongliang Zhang $^{3 *}$ (D)
}

\begin{abstract}
Jiao and colleagues reported a case of hemorrhagic fever with renal syndrome who developed respiratory failure and symmetrical flaccid paralysis of all extremities. Electrophysiology revealed peripheral nerve injuries mainly in axons. They reached a diagnosis of Guillain-Barré syndrome (GBS) associated with hemorrhagic fever with renal syndrome. Although the case is interesting, the diagnosis of GBS in such a patient should be with caution. Critical illness polyneuropathy (CIP) is an important and common differential diagnosis of GBS, especially in intensive care settings. Differentiating CIP from the axonal variants of GBS may be difficult on purely clinical grounds. Albuminocytologic dissociation in CSF can help differentiate GBS from other disorders.
\end{abstract}

Keywords: Hemorrhagic fever with renal syndrome, Guillain-Barré syndrome, Critical illness polyneuropathy, Albumino-cytologic dissociation

\section{Background}

Jiao and colleagues reported a case of hemorrhagic fever with renal syndrome who developed respiratory failure and symmetrical flaccid paralysis of all extremities [1]. Electrophysiology revealed peripheral nerve injuries mainly in axons. They reached a diagnosis of GuillainBarré syndrome (GBS) associated with hemorrhagic fever with renal syndrome. Although the case is interesting, the diagnosis of GBS in such a patient should be with caution.

GBS is an immune-mediated disorder of the peripheral nervous system and respiratory failure requiring mechanical ventilation is a serious complication of GBS [2]. However, the reported patient developed respiratory failure and refractory shock first, and then received mechanical ventilation. As per the description provided by the authors, the patient presented with symmetrical flaccid paralysis of all extremities but normal spontaneous respiration after cease of sedation, analgesia and muscle relaxants, on day 12 [1]. Usually, respiratory muscles are

\footnotetext{
* Correspondence: drzhl@hotmail.com

${ }^{+}$Linpei Jia and Rufu Jia contributed equally to this work.

${ }^{3}$ Department of Life Sciences, the National Natural Science Foundation of

China, Shuangqing Road 83\#, Beijing 100085, China

Full list of author information is available at the end of the article
}

easily involved in a quadriplegic GBS patient. Of note is that the patient was absent from diplopia or facioplegia. In this regard, critical illness polyneuropathy (CIP) should be highly suspected.

CIP and critical illness myopathy (CIM) are frequent complications of critical illness involving both of the motor and sensory axons $[3,4]$. The cardinal clinical sign of CIP and CIM presents as flaccid and symmetric weakness of extremities as well as respiratory muscles $[3,5]$. Patients with CIP may show a distal sensory loss, e.g. pain, temperature, or vibration $[3,5]$. CIP and/or CIM occur in approximately $70 \%$ of patients with sepsis or systemic inflammatory response syndrome (SIRS) [2, 5], $60 \%$ of acute respiratory distress syndrome $[2,5]$, and up to $100 \%$ of patients with multiple organ failure $[2,5]$. CIP and CIM alone, or in combination prolong weaning from mechanical ventilation and physical rehabilitation $[3,5]$.

We previously reported a case of critical illness polyneuropathy and myopathy with reversible tetraplegia after percutaneous nephrostolithotomy and septic shock [6]. The axonal variants of GBS might be difficult to distinguish from CIP due to the similar clinical manifestations and electrophysiological signs. Although the clinical presentation and electrophysiology would not 
give supportive discrimination, cerebral spinal fluid (CSF) might be of help. A clinical hallmark of GBS is albumino-cytologic dissociation in CSF [7]. In this case, the patient failed to receive a lumbar puncture. Therefore, the differential diagnosis of CIP cannot be ruled out.
In summary, CIP is an important and common differential diagnosis of GBS, especially in intensive care settings. Differentiating CIP from the axonal variants of GBS may be difficult on purely clinical grounds. Albumino-cytologic dissociation in CSF can help differentiate between these two diseases.

\section{Authors' response}

Lei Wu, Xuan Sun and Jie Hu

Zhang and colleagues suggested a reasonable doubt about the patient's diagnosis that we should take critical illness polyneuropathy (CIP) or critical illness myopathy (CIM), instead of Guillain-Barré syndrome (GBS), into consideration based on the scenario of critical illness. Although it is difficult to distinguish CIP/CIM and GBS because of their similar clinical manifestations (such as axonal motor and sensory polyneuropathy), some factors should be taken into account when we deal with this dilemma.

First, prolongation of F-waves on electromyography (EMG) is the most important feature of GBS other than CIP/CIM [8]. Nerve root impairment is one of the characteristics of GBS, and it usually appears as prolongation of F-waves on EMG [9] and albuminocytological dissociation in cerebrospinal fluid (CSF). Of note is absence of prolongation of $\mathrm{F}$-waves is one of the diagnostic criteria for CIP [8]. In our case, the patient showed absence of $F$ wave in right tibial nerve and prolongation of F-wave in left tibial nerve [1], which is a strong supportive evidence of GBS.

Second, the lack of evidence of albuminocytological dissociation should not be an exclusion criterion for GBS. Based on our current knowledge, only $64 \%$ of patients with GBS have the feature with albuminocytological dissociation [10]. According to the recently proposed new diagnostic classification system, GBS diagnosis can be decided with clinical ground and EMG manifestations, without the need for additional laboratory tests, and whether or not they fulfill existing diagnostic criteria [11].

Third, we cannot arbitrarily exclude the diagnosis of GBS due to the absence of cranial nerve deficits, such as diplopia or facioplegia. GBS is highly diverse in terms of the presence, distribution and extent of cranial nerve deficits, sensory symptoms, weakness, ataxia, and the course of the disease [10]. Only $50 \%$ of the GBS patients present cranial nerve deficits [12].

Fourth, the presence or absence of respiratory problems cannot be used in differential diagnosis of ICUAW and GBS since respiratory muscle weakness also occurs commonly in patients with CIP/CIM [13].

Fifth, good response to intravenous immunoglobin (IVIG) therapy strongly supported the diagnosis of GBS. For GBS, IVIG or plasma exchange (PE) is the optimal management approach, alongside supportive care [14]. CIP and CIM are pathophysiologic definition describing the weak critically ill patient with evidence of associated neuromuscular dysfunction, which represent the most prominent causes of intensive care unit acquired weakness (ICUAW). In intensive settings, sepsis, shock, hyperglycemia, the presence and degree of multiorgan failure, immobilization, and the utilization of steroids or neuromuscular blocker are the potential risk factors of ICUAW [15]. Unlike GBS, there are no proven therapies that could reverse ICUAW, i.e., CIP and CIM [8]. Treatment of underlying disease such as sepsis and shock, control of hyperglycemia, minimization of sedation, and early mobilization might be potential therapeutic strategies for ICUAW [15].

Last, etiological agents might highlight the diagnosis of GBS. Wachira et al. found that virus (such as cytomegalovirus and influenza virus) and Campylobacter jejuni infection were the most commonly etiological agents in GBS development in a meta-analysis [14]. However, this meta-analysis did not include the six cases of GBS subsequent to Hantavirus infection because they were single case reports.

In summary, we hold the opinion that our patient is a case of GBS (AMSAN) associated with Hantavirus infection. In intensive care settings, ICUAW should be suspected once the patients presented flaccid quadriparesis and neuromuscular respiratory failure, especially after recovery of sepsis, shock and multiorgan failure. Of note is that in patients with virus or Campylobacter jejuni infection, EMG should be performed to identify GBS. In that case, targeting therapy, like IVIG or PE, could be immediately initiated to get a better prognosis.

\section{Abbreviations \\ CIM: Critical illness myopathy; CIP: Critical illness polyneuropathy; CSF: Cerebral spinal fluid; GBS: Guillain-Barré syndrome; SIRS: Systemic inflammatory response syndrome}

\section{Acknowledgements}

Nil.

Authors' contributions

$\mathrm{LJ}$ and RJ drafted the manuscript. $\mathrm{HZ}$ conceived the idea and critically revised the manuscript. All authors approved the final version of manuscript for submission. 
Funding

The study was supported by grants from Wu Jieping Medical Foundation

Clinical Research Funding (No. 320.6750.16050).

\section{Availability of data and materials}

Not applicable.

\section{Ethics approval and consent to participate}

Not applicable.

\section{Consent for publication}

Not applicable.

\section{Competing interests}

The authors declare that they have no competing interests.

\section{Author details}

'Department of Nephrology, Xuanwu Hospital of Capital Medical University, Changchun Street 45\#, Beijing 100053, China. ${ }^{2}$ Central Hospital of Cangzhou, Xinhua Middle Street 201\#, Cangzhou 061001, Hebei Province, China. ${ }^{3}$ Department of Life Sciences, the National Natural Science Foundation of China, Shuangqing Road 83\#, Beijing 100085, China.

Received: 13 April 2018 Accepted: 26 June 2019

Published online: 05 August 2019

\section{References}

1. Jiao J, Wu L, Yin J, Quan X, Chen W, Hu J. Guillain-Barre syndrome associated with hemorrhagic fever with renal syndrome in China: a case report. BMC Infect Dis. 2018;18:143.

2. Wu X, Li C, Zhang B, Shen D, Li T, Liu K, Zhang HL. Predictors for mechanical ventilation and short-term prognosis in patients with GuillainBarré syndrome. Crit Care. 2015;19:310.

3. Hermans G, De Jonghe B, Bruyninckx F, Van den Berghe G. Clinical review: critical illness polyneuropathy and myopathy. Crit Care. 2008;12:238.

4. Witt NJ, Zochodne DW, Bolton CF, Grand'Maison F, Wells G, Young GB, Sibbald WJ. Peripheral nerve function in sepsis and multiple organ failure. Chest. 1991;99:176-84.

5. Zhou CK, Wu LM, Ni FM, Ji W, Wu J, Zhang HL. Critical illness polyneuropathy and myopathy: a systematic review. Neural Regen Res. 2014;9:101-10.

6. Li H, Wu LM, Kong XB, Hou Y, Zhao R, Li HY, Zhang HL. Reversible tetraplegia after percutaneous nephrostolithotomy and septic shock: a case of critical illness polyneuropathy and myopathy with acute onset and complete recovery. BMC Nephrol. 2013;14:36.

7. Zhang HL, Zheng XY, Zhu J. Th1/Th2/Th17/Treg cytokines in Guillain-Barré syndrome and experimental autoimmune neuritis. Cytokine Growth Factor Rev. 2013;24:443-53.

8. Lacomis D. Neuromuscular disorders in critically ill patients: review and update. J Clin Neuromuscul Dis. 2011;12(4):197-218.

9. Gordon PH, Wilbourn AJ. Early electrodiagnostic findings in Guillain-Barre syndrome. Arch Neurol. 2001;58(6):913-7.

10. Den Berg BV, Walgaard C, Drenthen J, Fokke C, Jacobs BC, Van Doorn PA. Guillain-Barré syndrome: pathogenesis, diagnosis, treatment and prognosis. Nat Rev Neurol. 2014;10(8):469-82.

11. Wakerley BR, Uncini A, Yuki N. Guillain-Barre and miller fisher syndromes-new diagnostic classification. Nat Rev Neurol. 2014;10(9):537-44.

12. Asbury AK, Cornblath DR. Assessment of current diagnostic criteria for Guillain-Barré syndrome. Ann Neurol. 1990;27.

13. Jung B, Moury PH, Mahul M, de Jong A, Galia F, Prades A, Albaladejo P, Chanques G, Molinari N, Jaber S. Diaphragmatic dysfunction in patients with ICU-acquired weakness and its impact on extubation failure. Intensive Care Med. 2016;42(5):853-61.

14. Willison HJ, Jacobs BC, van Doorn PA. Guillain-Barre syndrome. Lancet (London, England). 2016;388(10045):717-27.

15. Kramer CL. Intensive care unit-acquired weakness. Neurol Clin. 2017;35(4): 723-36.

\section{Publisher's Note}

Springer Nature remains neutral with regard to jurisdictional claims in published maps and institutional affiliations.

\section{Ready to submit your research? Choose BMC and benefit from:}

- fast, convenient online submission

- thorough peer review by experienced researchers in your field

- rapid publication on acceptance

- support for research data, including large and complex data types

- gold Open Access which fosters wider collaboration and increased citations

- maximum visibility for your research: over $100 \mathrm{M}$ website views per year

At BMC, research is always in progress.

Learn more biomedcentral.com/submissions 